Bachmann, B. J. (1955). J. gen. Microbiol. 13, 541-551

\title{
Studies on Cytophaga fermentans, n.sp., a Facultatively Anaerobic Lower Myxobacterium
}

\author{
By BARBARA J. BACHMANN* \\ Hopkins Marine Station, Pacific Grove, California, U.S.A.
}

SUMMARY: A previously undescribed myxobacterium was isolated from marine mud and studied in pure culture. This organism is a typical non-fruiting, amicrocystogenous lower myxobacterium and has been classified in the genus Cytophaga under the name $C$. fermentans, n.sp., to indicate its ability, unique among the cytophagas so far studied, to grow anaerobically at the expense of organic compounds. The organism can utilize as carbon and energy sources simple sugars and starch, but not cellulose, agar or chitin. Ammonium salts, asparagine or glutamine are satisfactory nitrogen sources; urea, nitrates and amino acids are not. Thiamine and relatively high concentrations of iron and $\mathrm{CO}_{2}$ are required for growth in a defined medium. Glucose is fermented to acetic, propionic and succinic acids, in approximately equimolar quantities, plus a small amount of lactic acid. In addition, a large quantity of mucilage, which appears to be a nitrogen-containing substance, is produced during the fermentation.

The myxobacteria may be readily distinguished morphologically from the true bacteria and from almost all other micro-organisms. The flexible vegetative cells, lacking flagella or a rigid cell wall and showing gliding motility on solid surfaces, distinguish all members of the group.

Classification of the higher myxobacteria has been based mainly on the morphology of their fruiting structures. The lower myxobacteria, in contrast, are largely indistinguishable from one another morphologically, and all nonfruiting, amicrocystogenous forms are assembled in the one genus Cytophaga (Stanier, 1942). Biochemical characteristics of the higher myxobacteria have been very little studied, largely because of the difficulties of growing them in well-defined media, although recent work has indicated that these difficulties may not be as great as was formerly supposed (Oxford \& Singh, 1946). The lower myxobacteria, on the other hand, have proved more amenable to experimental study, and it has become increasingly apparent that they comprise many types of great biochemical diversity. Future classification will, therefore, doubtless be based on physiological criteria.

The best known lower myxobacteria are the cellulose-decomposing cytophagas, an ecological-physiological group for which adequate enrichment techniques exist (Fåhraeus, 1947). Less well known are the chitin-decomposing soil forms (Stanier, 1947) and the agar-decomposing marine forms (Stanier, 1942). A number of lower myxobacteria has also been described which attack none of these complex substances and about whose ecology and physiology little is known (Imsenecki \& Solnzeva, 1945; Starr, 1953).

* Present address: Department of Bacteriology, University of California, Berkeley, California. 
Information that there exists in marine muds a facultatively anaerobic agar-decomposing lower myxobacterium presented an interesting new aspect of the biochemical diversity of the group, as all previously studied myxobacteria have been considered to be aerobic. Both Dr S. R. Elsden and Dr H. Larsen (personal communications) have encountered such a myxobacterium, tentatively identified as a cytophaga, in enrichment cultures aimed at the isolation of green bacteria. The present work was begun in an effort to reisolate and characterize this organism, which was lost before it could be studied. Although Elsden's and Larsen's organism was not found by the writer, an equally interesting facultatively anaerobic lower myxobacterium was obtained and has been studied in some detail. The characterization of this organism is the subject of the present report.

\section{Isolation and cultivation}

The organism was isolated from a bottle enrichment culture similar to that employed by Larsen (1952) for the enrichment of green sulphur bacteria and in which he found the anaerobic cytophaga previously mentioned. The medium had the following composition (g.): $\mathrm{NaCl}, 3 ; \mathrm{NaHCO}_{3}, 0 \cdot 2 ; \mathrm{KH}_{2} \mathrm{PO}_{4}, 0 \cdot 1$; $\mathrm{NH}_{4} \mathrm{Cl}, 0 \cdot 1 ; \mathrm{MgCl}_{2}, 0 \cdot 05 ; \mathrm{FeCl}_{3} \equiv 50 \mu \mathrm{g} . \mathrm{Fe}$; tap water to $100 \mathrm{ml}$; $\mathrm{pH} \mathrm{7 \cdot 0}$. Powdered agar was added to the bottles as a source of carbon and energy, since Larsen's and Elsden's organism had proved to be an agar-decomposer. Many bottle cultures were prepared using this and similar media and inocula from various marine sources. In a number of these cultures myxobacteriumlike cells were seen, but only in one did a myxobacterium develop to the extent of becoming the predominant organism.

After a number of serial transfers through bottles of the above medium, the successful enrichment culture was streaked on plates of rich organic media containing peptone or yeast extract. On most of these plates a rapid development of spreading eubacterial forms occurred and no myxobacteria were seen. On one series of plates, however, composed of the original enrichment medium $+\mathbf{0 . 5} \%$ peptone and $2 \%$ agar and lacking the $\mathrm{NaHCO}_{3}$, a myxobacterium slowly developed as almost the only form. Successive streak plates demonstrated that the organism was in pure culture. The yellow colonies lay in shallow craters in the agar, in contrast to the organism seen by Larsen and Elsden, which was reported to produce a pink pigment and to decompose agar rapidly and extensively.

Subculture by streaking on plates of a wide variety of organic media soon demonstrated that development was most satisfactory in a medium containing $1 \%$ yeast extract. The following medium (medium A) was used for the maintenance of stock cultures throughout most of this work (g.): yeast extract, 1 ; $\mathrm{NaCl}, 2 ; \mathrm{K}_{2} \mathrm{HPO}_{4}, 0.02 ; \mathrm{MgSO}_{4}, 0.05 ; \mathrm{NH}_{4} \mathrm{Cl}, 0 \cdot 1 ; \mathrm{FeCl}_{3} \equiv 50 \mu \mathrm{g}$. Fe; tap water to $100 \mathrm{ml}$.; $\mathrm{pH} \mathrm{7 \cdot 4}$. For slope cultures and stab cultures, both of which were carried at all times, 2 and $1 \%$ agar were added, respectively. Cultures were transferred weekly and were incubated at $30^{\circ}$ or at room temperature.

Although the method of isolation encouraged hopes that the organism could 
be obtained at will by use of an enrichment culture technique, efforts to repeat this isolation procedure or to develop a more reliable method for enrichment have failed. It appears that not enough is known about the organism at present to enable one to duplicate those conditions under which it thrives in nature and, conversely, the isolation gives no clue as to its biochemical role in nature.

\section{Nutrition and physiology}

This myxobacterium is at present unique in its group by virtue of its ability to develop anaerobically and it has accordingly been named Cytophaga fermentans n.sp.

The growth requirements of Cytophaga fermentans are relatively simple. As shown in Table 1, only a few of the simple carbohydrates and starch are suitable as carbon and energy sources. Neither cellulose, agar nor chitin will support growth. This organism, like the agar- and chitin-decomposing cytophagas described by Stanier (1942, 1947) does not show the sensitivity to autoclaved glucose exhibited by the cellulose-decomposing soil forms (Stanier, 1942; Fåhraeus \& Sijpesteijn, 1949). Ammonium salts, glutamine and asparagine are suitable nitrogen sources. Nitrates, urea and amino acids are not utilized.

Table 1. Ability of Cytophaga fermentans to utilize various compounds as carbon and energy sources as determined by growth in defined medium $\boldsymbol{B}$ without glucose, with addition of $1 \%$ of the compound tested, under semi-anaerobic conditions

\section{Utilized}

Glucose

Fructose

Sucrose

Lactose

Maltose

Cellobiose

Xylose

Arabinose

Mannose

Mannitol

Raffinose

Starch

$\begin{array}{ll}\text { Galactose } & \text { Aspartic acid } \\ \text { Rhamnose } & \text { Glutamic acid } \\ \text { Trehalose } & \text { Alanine } \\ \text { Dulcitol } & \text { Lactic acid } \\ \text { Sorbose } & \text { Pyruvic acid } \\ \text { Ribose } & \text { Succinic acid } \\ \text { Alginic acid } & \alpha \text {-Ketoglutaric acid } \\ \text { Cellulose* } & \text { Fumaric acid } \\ \text { Chitin } & \text { Malic acid } \\ \text { Agar } & \text { Acetic acid } \\ \text { Glycerol } & \text { Citric acid } \\ \text { Ethanol } & \end{array}$

* Cellulose added to the medium in the form of a filter-paper strip. The medium in all cases was adjusted to $\mathrm{pH} \mathbf{7 \cdot 2 - 7 \cdot 4}$.

The only organic growth factor required is thiamine and the only specific mineral requirement detected is for iron in relatively high concentration. A fairly high concentration of $\mathrm{CO}_{2}$ (supplied here as $c .1 \% \mathrm{NaHCO}_{3}$ ) is required for continued development of the organism in a defined medium. This requirement could be replaced by yeast extract but not by any of the organic compounds most commonly found to substitute for $\mathrm{CO}_{2}$ requirements in other organisms, e.g. succinate, malate, fumarate, citrate, glutamate. As was found 
for Escherichia coli by Lwoff \& Monod (1949), $\mathrm{CO}_{2}$ must here be essential for the formation of still other metabolites in the cell.

$\mathrm{NaCl}$ in concentrations from 2 to $3 \%$ permits good growth immediately, but the organism can be 'trained' to grow in concentrations as low as $1 \%$. $\mathrm{NaCl}$ in the defined medium can be replaced by $\mathrm{KCl}$ with no deleterious effects. On the whole, a fairly wide variation in the balance of minerals in the medium can be tolerated. The temperature range for growth is quite broad, the optimum being around $30^{\circ}$. The optimum $\mathrm{pH}$ range for the initiation of growth in the liquid defined medium is from $6 \cdot 7-8 \cdot 3$, again, a fairly wide range being tolerated.

The defined medium (medium B) used throughout the metabolic studies on Cytophaga fermentans has the following composition: glucose, 1 g.; $\mathrm{NaCl}, 2 \mathrm{~g}$; $\mathrm{NH}_{4} \mathrm{Cl}, 0.1 \mathrm{~g}$.; $\mathrm{KH}_{2} \mathrm{PO}_{4}, 0.02 \mathrm{~g}$.; $\mathrm{MgSO}_{4}, 0.05 \mathrm{~g}$.; $\mathrm{FeCl}_{3} \equiv 50 \mu \mathrm{g}$. Fe; thiamine $\mathrm{HCl}, 500 \mu \mathrm{g}$; Pyrex glass-distilled water, $78 \mathrm{ml}$.; $\mathrm{HCl}$ (conc.), $1 \mathrm{ml}$.; bromthymol blue, $5 \mathrm{ml}$. of a $0.1 \%$ solution. The medium is tubed in $6.4 \mathrm{ml}$. amounts and sterilized; the glucose is thus autoclaved in an acid solution and therefore has less tendency to caramelize. Just before inoculation, $1.6 \mathrm{ml}$. of a sterile $6 \cdot 25 \% \quad \mathrm{Na}_{2} \mathrm{CO}_{3} \cdot \mathrm{H}_{2} \mathrm{O}$ solution is added aseptically to each tube, bringing the $\mathrm{pH}$ value to $c$. $7 \cdot 4$. After inoculation the cotton stopper is pushed down into the tube and a rubber stopper inserted to prevent the escape of $\mathrm{CO}_{2}$. This medium has proved satisfactory through over 500 consecutive transfers. Maximum growth $\left(c .2 \times 10^{9}\right.$ cells $/ \mathrm{ml}$.) is attained in about $48 \mathrm{hr}$. at $30^{\circ}$ and is accompanied by a sharp drop in $\mathrm{pH}$ value because of acid production. The cells do not remain viable long after $\mathrm{pH} 6.0$ is reached; cultures in this medium are therefore transferred at about $48 \mathrm{hr}$. intervals and relatively large inocula are used.

A surprising result of the nutritional studies on Cytophaga fermentans is the unsuitability of agar as a carbon and energy source. The production of gelase fields and craters on the surface of agar plates and the softening of the underlying substrate would suggest agar utilization. Moreover, a solid medium which contains yeast extract + minerals + agar supports growth, while a liquid medium containing yeast extract and minerals alone will not. Yet the addition of washed agar to the defined medium $B$ (minus glucose) did not permit proliferation. Experiments with agar extracts indicate that impurities in commercial agar are sufficient to support a fair growth when the agar is present in $2 \%$ concentration. It must be concluded that the organism is not, as was first assumed, an agar decomposer in the sense that it can grow at the expense of this compound. The fact that galactose, the unit saccharide of agar, also was not suitable as a carbon and energy source lends support to this conclusion.

\section{Morphology}

Cytophaga fermentans grows on the surface of solid media in a manner sufficiently characteristic to differentiate it from almost all eubacterial forms. The first growth to appear upon transfer to a solid medium is a thin film, only a few cells thick at most and visible only by reflected light, which spreads out 
over the surface from the points of inoculation. When pieces of inoculum are placed gently upon the surface of the agar, the film spreads in all directions at a fairly uniform rate. When, however, inoculation is performed by streaking, the growth spreads more rapidly along the streaks made by the inoculating instrument than it does across the medium in a direction perpendicular to the streaks. Stanier (1942) studied the tendency of myxobacteria to migrate along lines of stress which have been induced in an agar substrate and coined the name 'elasticotaxis' for this oriented movement, the mechanism of which is still not understood.

After 4 or 5 days of incubation the character of the surface growth has changed conspicuously in the central portion of the 'colonies'. Many cells are collected into large swirls which appear at random throughout the film and which gradually increase in thickness until, after about 2 more days, the surface of the growth is dotted with large, shiny, bright yellow mucilaginous blobs of irregular shape. These blobs, which are translucent or opaque, sometimes give the appearance of isolated eubacterial colonies because of the relative transparency of the film on which they lie (P1. 1, fig. 1). During the development of this surface growth a change in the underlying agar has occurred so that the colony lies in a broad, shallow crater which extends c. 2-3 $\mathrm{mm}$. beyond the advancing colony edge. Co-extensive with the crater is a zone of clearing in the agar, otherwise slightly cloudy.

A microscopic examination of the organisms of which these colonies are composed yields the following picture. Cells from the advancing colony edge are slender flexible rods of low refractility with rounded ends, c. 5-15 $\mu$. long and $c .0 \cdot 6 \mu$. wide. The length of the cells is fairly uniform in a given area (Pl. 1, fig. 2). In material taken from the blobs in the central portion of a colony the cells are longer and more variable in length. They are there usually c. 15-30 $\mu$. long, although in very old cultures 'cells' up to $50 \mu$. in length have been observed. The cell width appears to remain constant under all conditions.

In the older portions of the colonies there are usually many involution forms. The $\mathrm{S}, \mathrm{U}, \mathrm{O}$ and $\mathrm{V}$ forms described in other cytophagas by previous workers occur frequently. Branching cells have never been seen in Cytophaga fermentans. The involution forms most frequently observed are small round bodies of low refractility, whose diameter extends from that of the vegetative cells $(c \cdot 0 \cdot 6 \mu$. $)$ up to $2 \cdot 5 \mu$. It seemed likely at first that these round bodies represented later stages of a life cycle of the organism; the fact that they appear in great numbers in almost all old cultures argues for this interpretation. However, their lack of refractility and their variability in size do not correspond with the appearance of the microcysts formed by other myxobacteria. In addition, old cultures containing many round bodies are very apt to be non-viable when transferred, which would support the view that these are non-viable cells which have lost the ability to maintain their rod shape. Under none of the conditions under which it was studied could $C$. fermentans be induced to form typical microcysts, which led to the conclusion that it is truly a 'lower' myxobacterium.

Cells grown in the synthetic medium do not produce the yellow pigment 
present in the surface colonies on agar media. The cells are shorter than those occurring on solid medium and quite uniform in a given culture (8-10 $\mu_{\text {. }}$ ) in older cultures cell length increases to $15-20 \mu$. The involution forms most frequently observed are the round bodies, which increase in number with the age of the culture and which may eventually outnumber the healthy vegetative cells.

A curious colonial variant was produced when liquid cultures in medium $\mathbf{B}$ were streaked on plates of medium $\mathbf{A}$. The resulting growth consisted of small, bright yellow, compact, opaque, convex, round, glistening colonies with an even edge. After growth for a week these colonies were only 1-2 $\mathrm{mm}$. in diameter, and were sunk in craters $c .2-4 \mathrm{~mm}$. in diameter. Such colonies resemble those of many eubacterial species, their only distinctive property being the craters produced in the agar substrate (Pl. 1, figs. 3, 4). The cells from such colonies, however, are indistinguishable from those from the normal colony type. The variant type is unstable and usually reverts, gradually, to the spreading type of growth. Stanier $(1942,1947)$ observed a similar variant colony type in a number of cytophagas studied by him.

Cytophaga fermentans exhibits on solid surfaces typical myxobacterial gliding motility accompanied by continuous flexing movements of low amplitude. No instance has been observed of cells moving in co-ordinated units such as Stanier (1942) found in the swarm extensions of Sporocytophaga myxococcoides. In liquid media the cells are non-motile but show vigorous flexing movements, particularly those cells one end of which has become stuck to the surface of a slide or coverslip.

The pigment produced by Cytophaga fermentans under aerobic conditions turns blue in the presence of concentrated sulphuric acid, can be extracted from the cells by methanol and then extracted from $90 \%$ methanol by light petroleum. The absorption spectrum is that of a carotenoid, resembling that of $\beta$-carotene.

\section{Fermentation of glucose}

Materials and methods. The fermentation of glucose was studied in bottle cultures of Cytophaga fermentans growing in defined medium B. The acid produced during the fermentation liberated such large quantities of $\mathrm{CO}_{2}$ from this bicarbonate-rich medium that it did not seem feasible to determine accurately the quantity of $\mathrm{CO}_{2}$ produced or taken up by the organism during dissimilation of the substrate. Therefore only the non-gaseous end-products of the bottle fermentations were analyzed.

Medium B (1500 ml.) minus the indicator was prepared and sterilized; a solution of $\mathrm{Na}_{2} \mathrm{CO}_{3}$ was autoclaved separately. Just before inoculation, the $\mathrm{pH}$ value of the flask of medium $\mathrm{B}$ was adjusted to $\mathrm{pH} 7 \cdot 4$ by the gradual addition of sterile $\mathrm{Na}_{2} \mathrm{CO}_{3}$. An inoculum consisting of $c .25 \mathrm{ml}$. of a $48 \mathrm{hr}$. culture in the same medium was then quickly added, and the flask was swirled to give thorough mixing. Enough of the contents was then poured into a sterile litre Pyrex bottle to fill it to the brim so that, upon insertion of the ground glass stopper, fluid was forced out of the neck of the bottle and no air 
space was left inside. A determination of the initial glucose was immediately performed on the excess inoculated medium, using the Luff-Schoorl method (Browne \& Zerban, 1941) modified for use within the range of 1-10 mg. glucose.

The bottles were incubated in a constant temperature room at $29^{\circ}$. Evolution of gas became apparent within $24 \mathrm{hr}$., and by the end of $48 \mathrm{hr}$. the cultures usually reached maximum turbidity. When the bottles were removed from the incubator, glucose determinations were immediately performed. Simultaneously, portions of the fermentation liquor were centrifuged for $1 \mathrm{hr}$. in a Servall high-speed angle centrifuge kept in a cold room at $14^{\circ}$. The 'sediment' obtained by this centrifugation consisted of a slimy mass of viscous material of approximately one-third the total volume of the fluid centrifuged. The supernatant was again centrifuged, a very slight amount of sediment being obtained this time. The two sediments were combined and treated with $1 \cdot 6 \mathrm{vol}$. of $95 \%$ ethanol $(\mathrm{v} / \mathrm{v})$ in water. The copious white stringy precipitate formed upon addition of ethanol was washed twice in $95 \%$ ethanol, once in absolute ethanol and once in ether. It was then vacuum dried in a weighed centrifuge tube to constant weight. A sample of the final supernatant fluid was treated with 1.6 vol. of $95 \%$ ethanol and the very slight amount of precipitate formed was treated in the same manner as the precipitate discussed above. These two precipitates were considered to represent the total amount of slime and cellular material produced during the fermentation. No method for separating the cells from the slime has as yet been devised.

A sample of the supernatant fluid was steam-distilled after acidification and the total amount of steam-volatile acids was determined by titration. The nature and ratios of the volatile acids present were determined by performing a Duclaux distillation on the steam-distillate (Knetemann, 1928). The residue from the steam-distillation was extracted with ether in a continuous liquidliquid extractor and the ether extract was analyzed for lactic acid by the method of Friedemann \& Graeser (1933) as modified by Stone (1938). Succinic acid was determined manometrically on the untreated fermentation fluid by using a beef heart succinic dehydrogenase preparation according to Cohen (Umbreit, Burris \& Stauffer, 1949).

The 2, 3-butyleneglycol occasionally found among the fermentation products was detected by the method of Kniphorst \& Kruisheer (1937). The presence of trace amounts of keto acids was detected by the method of Friedemann \& Haugen (1943). Paper chromatography of the 2, 4-dinitrophenylhydrazone derivatives by the method of Cavallini, Frontali \& Toschi (1949) revealed the presence of three compounds: the derivatives of pyruvic and $\alpha$-ketoglutaric acids and that of an unknown keto compound which moved just ahead of the pyruvic phenylhydrazone on the chromatograms. Since the 2, 3-butyleneglycol and keto acids were present only in trace amounts, they were not determined quantitatively.

The presence of glycerol was not demonstrated in the fermentation fluid using the periodate method of Neish (1950). In cultures in which essentially all of the glucose had been decomposed, the supernatant liquid from the centrifugations was made alkaline and distilled. The distillate was tested for the 
presence of alcohols (and aldehydes) by the dichromate method given by Neish (1950). No alcohol or aldehyde was detected in these cultures.

Results. A number of fermentation liquors of different ages with different initial substrate concentrations were analyzed. The results of three representative fermentation analyses are given in Table 2 . It can be seen that Cytophaga fermentans performs a fermentation essentially of the propionic acid type. The chief end-products are the ethanol-precipitatable material, consisting of slime + cells, and acetic, propionic and succinic acids. The ratios of the three major acidic end-products varied considerably from one fermentation to another, although the fermentations were carried out under conditions as nearly identical as possible. A small quantity of lactic acid was produced; as a rule the quantity did not vary much from fermentation to fermentation.

'Table 2. Fermentation balances on bottle cultures of Cytophaga fermentans growing in defined medium $B$

Experiment

Glucose added to medium $(\%, w / v)$

Available glucose disappeared (\%)

$\begin{array}{rcr}1 & 2 & 3 \\ 1 & 0 \cdot 5 & 1 \\ 92 & 100 & 84\end{array}$

Amounts of products $/ 100 \mu$ mole glucose utilized

\begin{tabular}{|c|c|c|c|c|c|c|}
\hline Products & $\mu$ mole & $\mu \mathrm{AC} *$ & $\mu$ mole & $\mu \mathbf{A C}$ & $\mu$ mole & $\mu \mathbf{A C}$ \\
\hline $\begin{array}{l}\text { Slime }+ \text { cells (as } \\
\text { glucose) }\end{array}$ & 16 & 96 & 22 & 132 & 15 & 90 \\
\hline Acetic acid & 48 & 96 & 45 & 90 & 36 & 72 \\
\hline Propionic acid & 48 & 144 & 55 & 165 & 44 & 132 \\
\hline Succinic acid & 48 & 192 & 39 & 156 & 55 & 220 \\
\hline Lactic acid & 5 & 15 & 5 & 15 & 15 & 45 \\
\hline Keto acids & Trace & - & Trace & . & Trace & • \\
\hline Acetoin & Trace & . & - & - & - & • \\
\hline Total $\mu \mathrm{A}$ carbon & \multicolumn{2}{|c|}{543} & \multicolumn{2}{|c|}{558} & \multicolumn{2}{|c|}{$\mathbf{5 5 9}$} \\
\hline $\begin{array}{l}\text { Carbon accounted } \\
\text { for }(\%)\end{array}$ & \multicolumn{2}{|c|}{91} & \multicolumn{2}{|c|}{93} & \multicolumn{2}{|c|}{93} \\
\hline Redox balance $\dagger$ & \multicolumn{2}{|c|}{$1 \cdot 00$} & \multicolumn{2}{|c|}{1.03} & \multicolumn{2}{|c|}{$0 \cdot 98$} \\
\hline
\end{tabular}

* The symbol ' $\mu \mathrm{AC}$ ' is used to express microgram atomic weight. It bears the same relation to gram atomic weight as does $\mu$ mole to gram molecular weight.

$\dagger$ Calculated according to the method of Barker \& Lipmann (1944).

The analysis of a bottle fermentation in which the $\mathrm{Na}_{2} \mathrm{CO}_{3}$ and $\mathrm{HCl}$ of the medium were replaced by $\mathrm{m} / 15$ phosphate buffer $(\mathrm{pH} \mathrm{7 \cdot 0)}$ gave the following quantities of acids $/ 100 \mu$ mole of substrate utilized: acetic $45 \mu$ mole, propionic $60 \mu$ mole, succinic $22 \mu$ mole. Thus, in a medium essentially lacking in $\mathrm{CO}_{2}$, less succinic acid was formed, proportionally; a finding which suggests the involvement of $\mathrm{CO}_{2}$ fixation in the production of this compound.

The dry weight of slime and cells produced accounted for as much as $25 \%$ and in no case less than $15 \%$ by weight of the glucose dissimilated. The chemical composition of slime + cells was considered to be the same as that of the substrate $\left(\mathrm{CH}_{2} \mathrm{O}\right)$ for the purpose of calculating fermentation balances. An analysis of the ethanol precipitate of slime + cells gave the following figures: 
carbon $45 \%$; hydrogen $6.95 \%$; nitrogen (Dumas method) $9 \cdot 45 \%$; oxygen, by difference, $38 \cdot 6 \%$. This corresponds closely to the formula $\mathrm{C}_{6} \mathrm{H}_{11} \mathrm{O}_{4} \mathrm{~N}$. The nitrogen content is close to that of whole bacterial cells (Buchanan \& Fulmer, 1928) which implies that the slime itself must be a nitrogen-containing substance. Protein determinations based on the biuret reaction and performed according to the method of Weichselbaum (1946) modified by Dr A. P. Pardee (personal communication) indicated that the mixture of slime + cells contained 70-90\% protein. A general test for carbohydrates based on the Molisch reaction (Kabat \& Mayer, 1948) showed c. 10-15\% carbohydrate in the mixture (calculated as glucose). Although the formula $\mathrm{C}_{6} \mathrm{H}_{11} \mathrm{O}_{4} \mathrm{~N}$ cannot represent more than an approximation of the average composition of the slime, it serves to show that the practice of considering it as 'carbohydrate' for the calculation of redox balances cannot have resulted in appreciable discrepancies.

\section{Taxonomy and diagnosis}

Cytophaga fermentans has been assigned to the order Myxobacteriales by virtue of its extremely flexible slender cells of low refractility, lacking a rigid cell wall and showing flexing and gliding motility. The only other groups which possess these morphological characteristics are the gliding Vitreoscillaceae described by Pringsheim (1951), and the blue green algae. These three groups, the Myxobacteriales, the Myxophyceae and the Vitreoscillaceae, seem therefore closely related, but much more will have to be known about the members of all three groups before the nature of their relationships can be clearly formulated and before one can with assurance classify all organisms showing the above characteristics.

The myxobacteria which do not possess a complex life cycle are classified in the family Cytophagaceae (Stanier, 1942). The members of this family are all included in one genus, Cytophaga, and so far no obvious natural separations indicating the need for more than one genus have been detected. Although it seems likely that as more non-fruiting myxobacteria are isolated and studied it will be convenient to place them in groups made along the lines of ecological types, such as the cellulose-decomposing soil forms and the marine agardecomposing forms, for example, it seems wise for the time being to avoid confusion by keeping the classification as simple as possible and by refraining from making further taxonomic divisions before the significance of the criteria used can be fully assessed.

For these reasons the organism has been classified as a member of the genus Cytophaga. To emphasize its distinctive ability to develop anaerobically at the expense of sugars, it has been named Cytophaga fermentans n.sp. The description is as follows.

Morphology: slender flexible rods of low refractility with rounded ends. Width $0.5-0.7 \mu$; length extremely variable, averaging 8-15 $\mu$. in young culture to $30 \mu$. in old cultures. Extremely long forms occasionally seen. Gram-negative. Stains evenly with crystal violet or carbol fuchsin. Young cells show gliding motility on surfaces and active flexing. 
Growth on yeast extract agar plates : a thin smooth glistening transparent film, spreading over agar surface. Later, mucilaginous opaque bright yellow blobs of various sizes and shapes appear at random in central portion of film. Colonies lie in shallow craters extending $c$. 1-2 mm. beyond advancing colony edge. Cells on agar surfaces display elasticotaxis. An unstable variant colony type appearing after passage through defined liquid medium consists of round, glistening, convex, bright yellow, mucilaginous colonies with entire edge.

Growth in yeast extract agar stabs: a diffuse cylinder of creamy white growth spreading out from line of inoculation.

Carbon and energy sources: under anaerobic conditions simple sugars (including glucose, sucrose, lactose, maltose) and starch utilized. Cellulose, agar, and chitin not utilized.

Nitrogen sources: ammonium salts, asparagine and glutamine utilized. Nitrates, amino acids and urea not utilized.

Growth factors : thiamine required. $\mathrm{High} \mathrm{CO}_{2}$ tension required for continued growth in defined medium.

Nitrites not produced from nitrates.

Catalase formed.

Optimum salt concentration range: $2 \cdot 5-3 \% \mathrm{NaCl}$.

Optimum temperature: Around $30^{\circ}$.

Optimum $\mathrm{pH}$ value: Around 7-8.

Facultatively anaerobic. Glucose fermented with production of acetic, propionic and succinic acids in approximately equimolar quantities. Large quantity of mucilage and small amount of lactic acid also produced. The pigment characteristic for cells grown aerobically on yeast agar is not produced under anaerobic conditions.

Source: Marine mud.

Habitat: Probably decaying marine vegetation.

I wish to express my gratitude to Professor C. B. van Niel under whose direction this work was performed. I should also like to thank Professors R. Y. Stanier and M. Doudoroff for their generous advice and assistance. This work was performed in part on Predoctoral Fellowships in the Biological Sciences granted by the Atomic Energy Commission and by the National Science Foundation. The paper is based on work submitted in partial fulfilment of the requirements for the degree of Doctor of Philosophy to Stanford University.

\section{REFERENCES}

Barker, H. A. \& Lipmann, F. (1944). On lactic acid metabolism in propionic acid bacteria and the problem of oxido-reduction in the system fatty-hydroxy-keto acid. Arch. Biochem. 4, 361.

Browne, C. A. \& Zerban, F. W. (1941). Physical and Chemical Methods of Sugar Analysis. New York: John Wiley and Sons Inc.

Buchanan, R. E. \& Fulmer, E. I. (1928). Physiology and Biochemistry of bacteria, vol. I, p. 73. Baltimore: Williams and Wilkins Company.

Cavallini, D., Frontali, N. \& Toschi, G. (1949). Determination of keto-acids by partition chromatography on filter paper. Nature, Lond. 163, 568.

FÅnraeus, G. (1947). Studies in the cellulose decomposition by Cytophaga. Symb. bot. upsaliens. 9, no. 2. 
Journal of General Microbiology, Vol. 13, No. 3
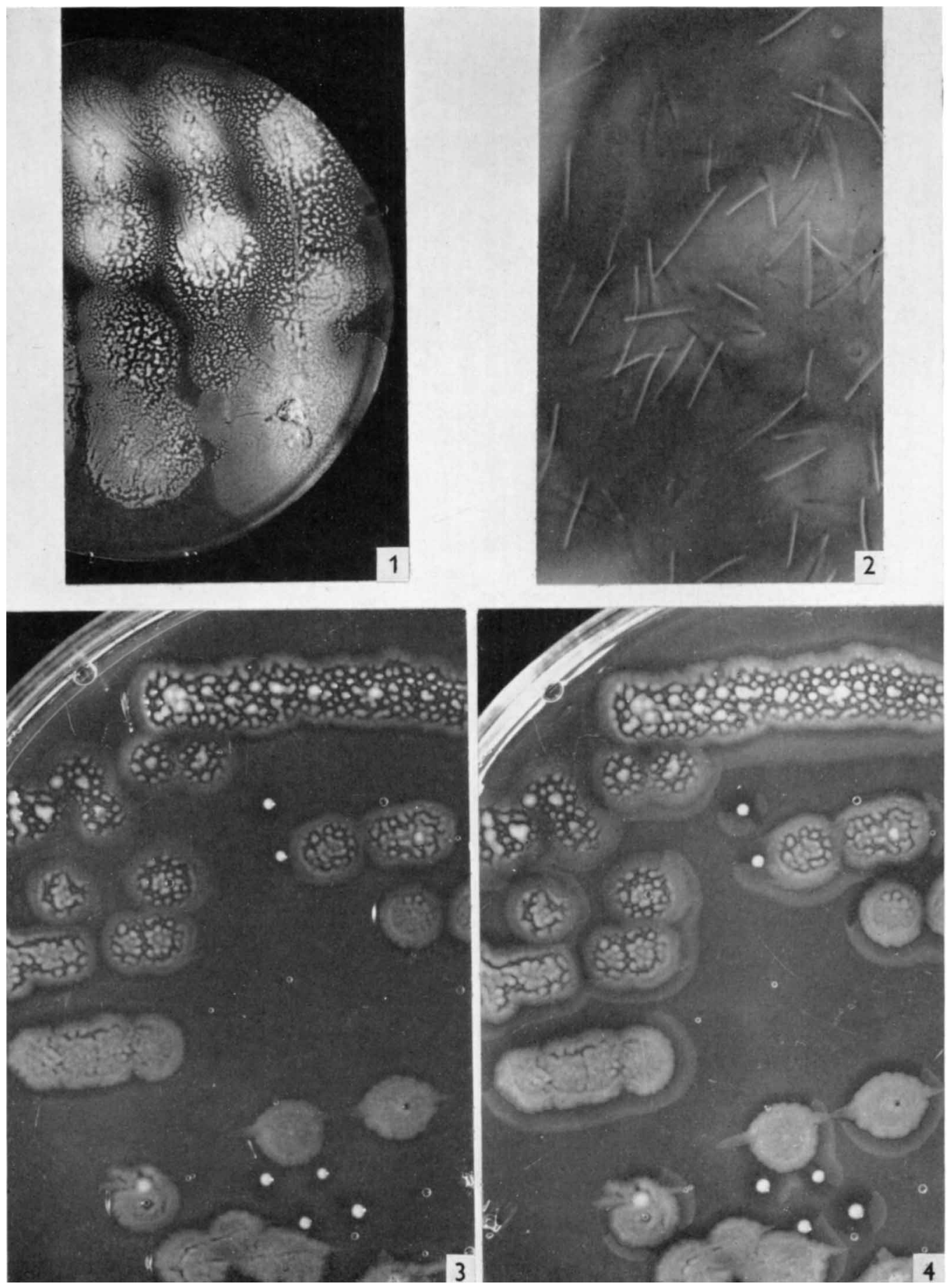

B. J. Bachmann-Cytophaga flkihentans, N.sp. Plate 1 
Fånraeus, G. \& SiJpesteijn, A. K. (1949). Adaptation of Sporocytophaga myxococcoides to sugars. J. gen. Microbiol. 3, 224.

Friedemann, T. E. \& Graeser, J. B. (1933). The determination of lactic acid. J. biol. Chem. 100, 291.

Friedemann, T. E. \& Haugen, G. E. (1943). Pyruvic acid. II. The determination of keto acids in blood and urine. J. biol. Chem. 147, 415.

ImSENECKI, A. A. \& Solnzeva, L. I. (1945). On the imperfect forms of myxobacteria. Microbiology, Moscore, 14, 220; cf. Stanier, 1947.

KABAt, E. A. \& MAYER, M. M. (1948). Experimental Immunochemistry. Springfield: Charles C. Thomas.

Knetemann, A. (1928). The Duclaux method for the estimation of volatile fatty acids and its application to the estimation of butter in margarine. Rec. Trav. chim. Pays-Bas 47, 950.

Kniphorst, L. C. E. \& Kruisheer, C. I. (1937). Die Bestimmung von 2, 3-Butylenglykol, Acetylmethylcarbinol und Diacetyl in Wein und anderen Gärungsprodukten. II. Entwicklung der Methodik. Untersuch. Lebensmitt. 73, 1.

Larsen, H. (1952). On the culture and general physiology of the green sulfur bacteria. J. Bact. 64, 187.

Lwoff, A. \& Monod, J. (1949). The problem of heterocarboxylic metabolites. Arch. Biochem. 22, 482.

Neish, A. C. (1950). Analytical methods for bacterial fermentations. Nat. Res. Coun. Canada, Rep. no. 46-8-3, revised.

Oxford, A. E. \& Singh, B. N. (1946). Factors contributing to the bacteriolytic effect of species of myxococci upon viable eubacteria. Nature, Lond. 158, 745.

Pringsheim, E. J. (1951). The Vitreoscillaceae: a family of colourless, gliding filamentous organisms. J. gen. Microbiol. 5, 124.

Stanier, R. Y. (1942). The cytophaga group: a contribution to the biology of myxobacteria. Bact. Rev. 6, 143.

Stanier, R. Y. (1947). Studies on non-fruiting myxobacteria. I. Cytophaga johnsonae, n.sp., a chitin-decomposing myxobacterium. J. Bact. 53, 297.

Starr, T. J. (1953). A study of marine myxobacteria. Thesis, University of Washington, Seattle.

Stone, W. E. (1938). The effects of anaesthetics and of convulsants on the lactic acid content of the brain. Biochem. J. 32, 1908.

Umbreit, W. W., Burris, R. H. \& Stauffer, J. F. (1949). Manometric Techniques and Tissue Metabolism. Minneapolis: Burgess Publishing Company.

Weichselbaum, T. E. (1946). An accurate and rapid method for the determination of proteins in small amounts of blood serum and plasma. Amer. J. clin. Path. (tech. Suppl.), 16, 40.

\section{EXPLANATION OF PLATE}

Fig. 1. Cytophaga fermentans on plate of medium A showing typical spreading type of growth; age 2 weeks.

Fig. 2. Phase-contrast photomicrograph of organisms grown on medium A; age 1 week. $\times 1200$.

Fig. 3. Cytophaga fermentans on plate of medium $\mathbf{A}$ after passage through defined medium $\mathbf{B}$, showing both small compact colonies and some which have reverted to spreading type of growth.

Fig. 4. Same field as in Fig. 3, photographed to show the craters produced in the agar substrate. 